\title{
Suitable Turbine Selection based on the Parameters of a Potential Site at Sarawak, Malaysia
}

\author{
Kamran Ahmed Samo \\ Department of Electrical Engineering \\ Quaid-e-Awam University of Engineering, Science and \\ Technology, Sindh, Pakistan \\ kamransamo2@gmail.com \\ Waqas Mughal \\ Department of Mechanical Engineering \\ Quaid-e-Awam University of Engineering, Science and \\ Technology, Nawabshah, Pakistan \\ engr.pirbux@outlook.com
}

\author{
Imran Ahmed Samo \\ Department of Energy \& Environment Engineering \\ Quaid-e-Awam University of Engineering, Science and \\ Technology, Nawabshah, Pakistan \\ imran.samo@yahoo.com \\ Andrew Ragai Henry Rigit \\ Mechanical Engineering Department \\ Universiti Malaysia Sarawak, \\ Sarawak, Malaysia \\ arigit@unimas.my
}

\author{
Arslan Ahmed Sohoo \\ Department of Electronic Engineering \\ Quaid-e-Awam University of Engineering, Science and Technology \\ Larkana Sindh, Pakistan \\ arslanahmed@quest.edu.pk
}

\begin{abstract}
The tidal range is a renewable energy source. In Malaysia, most of the produced renewable energy is generated from the exploitation of the tidal range. The main purpose of this research is to determine a suitable system to produce tidal range energy from a potential site. A turbine selection chart is used. The mean tidal range of Kuching Barrage is $4.2 \mathrm{~m}$ and the maximum flow rate over a gate is $226.9 \mathrm{~m}^{3} / \mathrm{s}$. Therefore, for the extraction of electrical power, a bulb-type turbine with a rated power of 5.2MW is identified as suitable to be deployed at the site.
\end{abstract}

\section{Keywords-tidal turbine; power; energy output; flow rate}

\section{INTRODUCTION}

Ocean renewable energy sources are globally established as mainstream sources of energy [1]. It is calculated that the theoretical ocean energy resources are over 30,000TWh/year and the net potential power is larger than the sum of wind and solar power [2]. Malaysia is one of the biggest producers of solar photovoltaic (PV) panels and is ranked as world's thirdlargest producer of solar PV energy [3]. However, ocean energy resources like tidal range energy can be used at a big scale for sustainable electrical power generation [4]. Tidal range power is produced due to the consistent rise and fall of seawater $[5,6]$. Tidal range power can be generated where tidal range flow is available [7]. Energy from tidal range can be used for electrical power generation. A potential site to generate renewable energy from tidal range at the East Coast of Malaysia can be determined [8]. Power could be generated from the existing or a new barrage, in the isolated regions of East Malaysia. This research found that bulb type turbine can be selected as the applicant turbine for Kuching Barrage. The selected turbine is proposed for electricity production in the Sarawak state of Malaysia.

The aim of this research is to determine a suitable turbine for a suitable location at Sarawak. Kuching Barrage is identified as a potential site that could yield $10.23 \mathrm{GWh}$ energy per year. The hypothesis of the research is that turbine selection is based on calculated parameters of potential sites, including tidal range and flow rate.

\section{LITERATURE REVIEW}

\section{A. Selection of the Tidal Range Turbine}

Turbine selection is mostly dependent on the accessible tidal range and flow rate. The flow rate is used to conclude the turbine capacity. Tidal barrage turbines usually have a low tidal range turbine. The lowest water range required for the operation of the turbine is between 1 and $1.5 \mathrm{~m}$. However, the most of tidal range power plants use low tidal range [8]. Turbine efficiency and price are side factors. There are various turbine types of calculated tidal range, flow rate, and appropriate power [10]. There are four different types of turbines: Pelton, Francis, Kaplan, and bulb type turbines [9]. The calculated ranges are between $50 \mathrm{~kW}$ and $1,000 \mathrm{MW}$ and the flow rate values vary from 1.0 to $1000 \mathrm{~m}^{3} / \mathrm{s}$. 


\section{B. Tidal Range Calculation}

Tidal range is defined as the difference between the water level in low and high tides. In the present study, one way power generation is assumed. Therefore, the difference in water level has been taken as the difference of high and low tide:

$$
h=h_{t}-l_{t}
$$

where $h$ is the tidal range $(\mathrm{m}), h_{t}$ is the high tide $(\mathrm{m})$, and $l_{t}$ is the low tide $(\mathrm{m})$.

$Q_{S}$ is defined as the discharge of water through a turbine. The water discharge through sluice gates $Q_{s}$ can be designed based on its association with the consistent mean tidal range.

$$
Q_{s}=C_{d} A \sqrt{2 g h}
$$

where $Q_{s}$ is the discharge through the sluice gate $\left(\mathrm{m}^{3} / \mathrm{s}\right), C_{d}$ is the discharge coefficient of the sluice gate (generally larger than 1), $A$ is the flow area through the hydraulic building $\left(\mathrm{m}^{2}\right)$; $g$ is the acceleration of gravity $\left(9.81 \mathrm{~m} / \mathrm{s}^{2}\right)$, and $h$ is the mean tidal range $(m)$ [11]. Similarly, by using (2), the flow rate can be calculated for each gate of the barrage.

\section{Turbine Rated Head and Power for a Single Turbine}

Equation (3) is used to calculate the turbine rated head for mean tidal range lesser than $9 \mathrm{~m}$. The constant value 0.66 can be used for a single high basin plant with one direction and for conventional bulb type turbine [12]. By using (3), the rated head of a turbine can be achieved. In (3), Mean Tidal Range is the same with $h(2)$ :

$$
H_{r} \approx 0.66 \times \text { Mean Tidal Range }
$$

Equation (4) is used to calculate the rated power for a single turbine in MW [12]. The power output can be achieved by using (4). The number 8.22 is a turbine constant value taken from [13], whereas the number 1000 in the denominator is used for conversion from $\mathrm{GW}$ to $\mathrm{MW}$ :

$$
P_{r}=\frac{8.22 Q_{s} H_{r}}{1000}
$$

\section{Methodology}

\section{A. Method of Turbine Selection}

The selection of a suitable turbine will be conducted using the calculated parameters (tidal range and flow rate) of a site. The turbine presentation plan will be used to choose the appropriate turbine agreeing to the parameters of the chosen site. The turbine should not conflict with the current size of the barrage gates. The turbine should be capable to work effectively at the lower tidal range of the selected site. In order to install a turbine at the selected site, the turbine parameters will be determined according to the parameters of the selected site.

\section{B. Tidal Range and Flow Rate Calculation}

For the calculation of tidal range, the tidal data for the year 2015 of the Kuching Barrage site will be utilized. The tidal pattern can be semi diurnal, diurnal and mixed, e.g. Sarawak is semi diurnal. Considering that Kuching Barrage is located in Pending, it is assumed that the tidal pattern observed at Pending is similar to the tidal pattern at Kuching Barrage. Statistical analysis will be performed with Sigma software for the calculation of the tidal range. Histograms of a tidal range of each month will be plotted with the annual tidal range information of the site. On the information of histogram plots the annual mean tidal range and the monthly mean tidal range will be determined. In Sigma, all data must be stacked first before any graph is to be plotted.

Tidal range and flow rate calculations are essential for turbine selection. The energy extraction from a potential site requires the data of tidal range and flow rate. Low and high tides of each day have been collected and the tidal range was determined by (1). Gate flow rate was calculated from (2). For the duration of the flushing process, the barrage gates are opened by $1 \mathrm{~m}$ from the upstream (basin side). The opening space of the barrage gates will be considered to discover the real discharge at the barrage gate. Table I presents the data of Pending site for the January of 2015. The second column shows the high tide water level and the third column shows the low tide water level. The tidal range in the third column is calculated from (1). The data show that the mean of the tidal

\begin{tabular}{|c|c|c|c|}
\hline Day & $\begin{array}{c}\text { High tide } \\
\text { water level }(\mathrm{m})\end{array}$ & $\begin{array}{c}\text { Low tide water level } \\
\text { calculation }(\mathrm{m})\end{array}$ & $\begin{array}{c}\text { Tidal range } \\
\text { (m) }\end{array}$ \\
\hline 1 & 5.2 & 1.6 & 3.6 \\
\hline 2 & 5.3 & 1.4 & 3.9 \\
\hline 3 & 5.5 & 1.2 & 4.3 \\
\hline 4 & 5.7 & 1.0 & 4.7 \\
\hline 5 & 5.8 & 0.9 & 4.9 \\
\hline 6 & 5.8 & 0.9 & 4.9 \\
\hline 7 & 5.8 & 0.9 & 4.9 \\
\hline 8 & 5.7 & 1.0 & 4.7 \\
\hline 9 & 5.6 & 1.2 & 4.4 \\
\hline 10 & 5.5 & 1.4 & 4.1 \\
\hline 11 & 5.3 & 1.7 & 3.6 \\
\hline 12 & 5.2 & 2.0 & 3.2 \\
\hline 13 & 5.0 & 2.3 & 2.7 \\
\hline 14 & 4.9 & 2.3 & 2.6 \\
\hline 15 & 4.9 & 2.2 & 2.7 \\
\hline 16 & 4.6 & 2.0 & 2.6 \\
\hline 17 & 4.9 & 1.7 & 3.2 \\
\hline 18 & 5.3 & 1.4 & 3.9 \\
\hline 19 & 5.7 & 1.0 & 4.7 \\
\hline 20 & 6.0 & 0.7 & 5.3 \\
\hline 21 & 6.2 & 0.4 & 5.8 \\
\hline 22 & 6.3 & 0.3 & 6.0 \\
\hline 23 & 6.3 & 0.3 & 6.0 \\
\hline 24 & 6.2 & 0.6 & 5.6 \\
\hline 25 & 6.0 & 1.0 & 5.0 \\
\hline 26 & 5.7 & 1.5 & 4.2 \\
\hline 27 & 5.4 & 1.6 & 3.8 \\
\hline 28 & 5.1 & 1.7 & 3.4 \\
\hline 29 & 4.8 & 1.8 & 3.0 \\
\hline 30 & 4.9 & 1.7 & 3.2 \\
\hline 31 & 5.1 & 1.9 & 3.5 \\
\hline
\end{tabular}
range is $4.1 \mathrm{~m}$.

TABLE I. HIGH AND LOW TIDE WATER LEVEL AND TIDAL RANGE OF PENDING SITE, JANUARY, 2015

\section{Turbine Rated Head and Power of One Turbine}

To calculate the turbine rated head, (3) will be used. For calculating therated power of a turbine, (4) will be used. 


\section{RESULTS AND DISCUSSIONS}

\section{A. Parameters at Kuching Barrage}

To select a suitable turbine for Kuching Barrage, it is important to determine the parameters of Kuching Barrage. The tide tables are used to calculate the tidal range of the Pending site.

\section{B. Tidal Range of Kuching Barrage}

To calculate the tidal range and to analyze the tidal pattern of Pending, the information from the tide tables of 2015 is used. The mean tidal range is $4.2 \mathrm{~m}$ and, as can be seen in Figure 1, the maximum tidal range is $6.2 \mathrm{~m}$. It can be seen that low tidal ranges (from $1.7 \mathrm{~m}$ to $2.0 \mathrm{~m}$ ) have low occurring frequency while higher ranges $(2.4 \mathrm{~m}-6.2 \mathrm{~m})$ are more frequent.

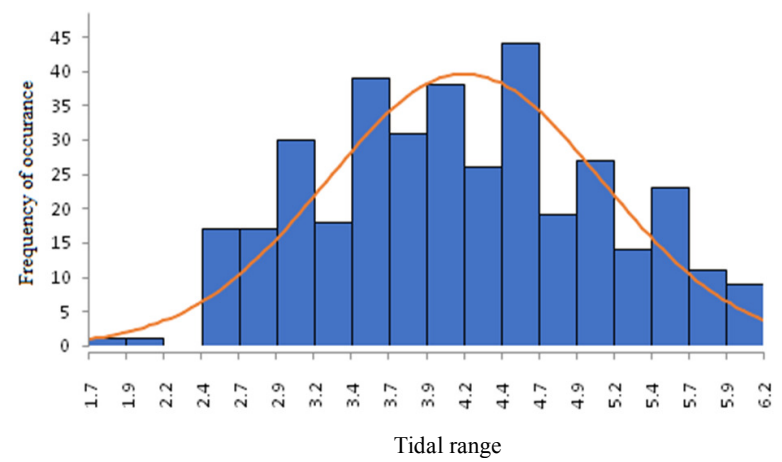

Fig. 1. Graph of calculated tidal range in 2015 at Pending.

Table II depicts the maximum, minimum, and the mean values for the tidal range of each month of the Pending region. The lowermost tidal range, observed in December, was $1.7 \mathrm{~m}$ and the maximum value, observed in October, was $6.2 \mathrm{~m}$. The highest peak mean tidal range recorded was $4.2 \mathrm{~m}$. The results do not relate to the monsoon, however they may seem like as coming from a hydroelectric dam. As the power generated from the barrage is one way (power generation is only generated during the low tide) and as per actual measurements of the tides it is visible that low tides are almost similar, which may be the reason of small variations in calculations.

TABLE II. PENDING SITE TIDAL RANGE IN 2015

\begin{tabular}{|c|c|c|c|}
\hline Month & Maximum & Minimum & Mean \\
\hline January & 6.0 & 2.6 & 4.1 \\
\hline February & 6.0 & 2.8 & 4.2 \\
\hline March & 5.8 & 2.9 & 4.1 \\
\hline April & 6.0 & 2.8 & 4.2 \\
\hline May & 5.8 & 2.7 & 4.2 \\
\hline Jun & 5.4 & 2.6 & 4.1 \\
\hline July & 5.6 & 2.7 & 4.1 \\
\hline August & 5.8 & 2.7 & 4.2 \\
\hline September & 6.0 & 2.6 & 4.1 \\
\hline October & 6.2 & 2.6 & 4.3 \\
\hline November & 6.0 & 2.0 & 4.2 \\
\hline December & 5.6 & 1.7 & 4.1 \\
\hline
\end{tabular}

\section{Water Flow Rate of Kuching Barrage}

The water flow through the barrage gate is calculated by
(2). During the flushing process, the barrage gates are mechanically unlocked by $1 \mathrm{~m}$ from the upstream [14]. The Kuching Barrage opening area of each gate is $25 \mathrm{~m}^{2}$ while the gate width is $25 \mathrm{~m}$. One more parameter in defining water flowing rate is the "discharge coefficient" which is supposed to be equal to 1 [11]. On $4.2 \mathrm{~m}$ tidal range and supposing discharge coefficients equal to 1 , the total flow of four gates of Kuching Barrage is calculated to be $907.7 \mathrm{~m}^{3} / \mathrm{s}$ (gate 5 is reserved for emergencies). The water flow calculated for each gate is $226.9 \mathrm{~m}^{3} / \mathrm{s}$.

\section{Turbine Selection based on Kuching Barrage Parameters}

A turbine should be capable to work powerfully at low tidal range values. The turbine should not disturb the barrage gates' size and ship lock. The turbine selection is based on tidal range and flow rate. For the selection of a suitable turbine, a presentation chart is used to choose the appropriate one. As shown in Figure 1, the mean tidal range is $4.2 \mathrm{~m}$ and the mean flow rate is $226.9 \mathrm{~m}^{3} / \mathrm{s}$. For these conditions, the most appropriate turbine is the bulb-type turbine. Therefore, it is recommended to be installed at the Kuching Barrage.

\section{E. Parameters of the Selected Turbine}

\section{1) Rated Head $\mathrm{H}_{r}$}

Equation (3) is used to calculate the turbine rated head for mean tidal range lower than $9 \mathrm{~m}$ and a single basin tidal power plant.

\section{2) Power of a Single Turbine}

Equation (4) is used to calculate the rated power of a turbine for $Q_{s}=226.9 \mathrm{~m}^{3} / \mathrm{s}$ and $H_{r}=2.772 \mathrm{~m}$. The rated power is measured in MW. Table III depicts the calculated (bulb type) turbine parameters and the Kuching Barrage parameters. The rated head is calculated by (3), the gate flow rate is designed by (2), and the throat area of the turbine is calculated with the help of the turbine diameter and the area of a circle. The rated power output for a single turbine is calculated by (4). The turbine diameter is logically measured based on the space between the LSD of Kuching Barrage gate and the lowest tide level. The mean tidal range is the average of all mean tidal range values. Gate flow rate is calculated by (2). The basin area is calculated with the help of Google Maps.

TABLE III. PENDING SITE TIDAL RANGE OF EACH MONTH OF 2015

\begin{tabular}{|c|c|c|}
\hline Parameter & Symbol & Value \\
\hline Rated head & $H_{r}$ & $2.772 \mathrm{~m}$ \\
\hline Throat area of the turbine & $F$ & $4.3 \mathrm{~m}^{2}$ \\
\hline Rated power output & $P_{r}$ & $5.2 \mathrm{MW}$ \\
\hline Turbine diameter & $D_{t}$ & $2.35 \mathrm{~m}$ \\
\hline Mean tidal range & $H$ & $4.2 \mathrm{~m}$ \\
\hline Gate flow rate & $Q_{s}$ & $226.9 \mathrm{~m}^{3} / \mathrm{s}$ \\
\hline Basin area & $A_{b}$ & $2.94 \mathrm{~km}^{2}$ \\
\hline
\end{tabular}

\section{F. Mechanical Components of the Selected Turbine and its Functions}

The main mechanical components of the bulb-type turbine are a Kaplan runner, guide vanes, a propeller shaft, bearings, and the generator. The draft tube is the runner opening passageway of the turbine, fronting to the sea region in the 
Kuching Barrage tidal energy plant system. The key purpose of the draft tube is to decrease the velocity out of the turbine throat space. The Kuching barrage draft tube is $11.32 \mathrm{~m}$ long. Guide vanes are important to modify the water flow in the runner agreeing to the design angles of the runner blades. The bulb-type turbine has two radial bearings to the horizontal shaft and provides thrust in the process $[15,16]$.

\section{G. Power Output Calculations}

The study exhibited that Kuching Barrage has the potential for power generation by the installation of tidal range turbines suitable for a tidal energy plant. The potential energy and the annual power output are calculated.

\section{H. Calculated Basin Area of Kuching Barrage}

The basin area of Kuching Barrage was measured as $2.94 \mathrm{~km}^{2}$. The total basin area bounded by the Kuching Barrage is $1430 \mathrm{~km}^{2}$. However, this may not be valid when used for power generation. Hence, it is assumed that the total bounded area may not be the effective area contributing power generation. The effective basin area has been assumed as $2.94 \mathrm{~km}^{2}$.

\section{CONCLUSION}

Pending's mean tidal range is about $4.2 \mathrm{~m}$ and the discharged flow rate of a single gate is $226.9 \mathrm{~m}^{3} / \mathrm{s}$. The bulbtype turbine is proposed as the most applicable turbine for Kuching Barrage. The calculated diameter of the bulb-type turbine is $2.35 \mathrm{~m}$. The bulb-type turbine is planned to be installed at four gates of Kuching Barrage. The rated power is about 5.2MW/turbine.

\section{REFERENCES}

[1] F. M. Sim, "Global Direction on Renewables," The Ingenieur, vol. 67, pp. 32-37, Jul. 2016.

[2] T. D. Corsatea and D. Magagna, "Overview of European innovation activities in marine energy technology," European Comission, Petten, Neatherlands, EUR 26724 EN, 2014.

[3] A. M. Hussain, "Clean energy," The Ingenieur, vol. 67, pp. 4-4, Jul. 2016.

[4] S. P. Neill et al., "Tidal range energy resource and optimization - Past perspectives and future challenges," Renewable Energy, vol. 127, pp. 763-778, Nov. 2018, http://doi.org/10.1016/j.renene.2018.05.007.

[5] O. Yaakob, T. M. A. Tengku Ab Rashid, and M. A. Abdul Mukti, "Prospects for Ocean Energy in Malaysia," presented at the International Conference on Energy and Environment 2006 (ICEE 2006), Bangi, Selangor, Malaysia, Aug. 2006.

[6] J. Xia, R. A. Falconer, and B. Lin, "Impact of different tidal renewable energy projects on the hydrodynamic processes in the Severn Estuary, UK," Ocean Modelling, vol. 32, no. 1, pp. 86-104, Jan. 2010 , http://doi.org/10.1016/j.ocemod.2009.11.002.

[7] P. Meisen and A. Loiseau. Ocean Energy Technologies for Renewable Energy Generation. Global Energy Network Institute, 2009.

[8] K. A. Samo, I. A. Samo, Z. A. Siyal, and A. R. H. Rigit, "Determination of Potential Tidal Power Sites at East Malaysia," Engineering, Technology \& Applied Science Research, vol. 10, no. 4, pp. 6047-6051, Aug. 2020, https://doi.org/10.48084/etasr.3674.

[9] J. Xia, R. A. Falconer, and B. Lin, "Impact of different operating modes for a Severn Barrage on the tidal power and flood inundation in the Severn Estuary, UK," Applied Energy, vol. 87, no. 7, pp. 2374-2391, Jul. 2010, http://doi.org/10.1016/j.apenergy.2009.11.024.

[10] B. S. A. Pereira, P. M. Sobrinho, and J. L. Silveira, "The use of LINGO programming language to develop a computer tool to provide a technical and economic analysis of a hydraulic potential that allows the application of Francis turbines and Kaplan turbines," in XI LatinAmerican Congress on Electricity Generation and Transmission, Nov. 2015, pp. 98-99.

[11] J. Xia, R. A. Falconer, B. Lin, and G. Tan, "Estimation of annual energy output from a tidal barrage using two different methods," Applied Energy, vol. 93, pp. 327-336, May 2012, http://doi.org/10.1016/ j.apenergy.2011.12.049.

[12] W.-O. Song and W. van Walsum, "2.5. Tidal power plants," in Renewable Energy, Berlin, Heidelberg: Springer, 2005, pp. 129-164.

[13] H. Swane, "Tidal power plant in Saemangeum," M.S. thesis, Technische Universiteit Delft (TU Delft), Delft, Neatherlands, 2007.

[14] H. Singh, The physical environment of Sarawak. Kota Samarahan, Sarawak, Malaysia: Universiti Malaysia Sarawak, 2012.

[15] S. Waters and G. Aggidis, "Tidal range technologies and state of the art in review," Renewable and Sustainable Energy Reviews, vol. 59, pp. 514-529, Jun. 2016, http://doi.org/10.1016/j.rser.2015.12.347.

[16] H. Amiri, R. Shafaghat, R. Alamian, S. Taheri, and M. S. Shadloo, "Study of horizontal axis tidal turbine performance and investigation on the optimum fixed pitch angle using CFD: A case study of Iran," International Journal of Numerical Methods for Heat \& Fluid Flow, Aug. 2019, http://doi.org/10.1108/HFF-05-2019-0447. 